\title{
HISTÓRIA E MEMÓRIA DO CENTRO EDUCACIONAL MARTINHO LUTERO NO CONTEXTO DA CONSTRUÇÃO DE PALMAS-TO
}

\author{
HISTORY AND MEMORY OF THE CENTRO EDUCACIONAL \\ MARTINHO LUTERO IN THE CONTEXT OF \\ THE CONSTRUCTION OF PALMAS-TO \\ HISTORIA Y MEMORIA DEL CENTRO EDUCACIONAL \\ MARTINHO LUTERO EN EL CONTEXTO DE \\ LA CONSTRUCCIÓN DE PALMAS-TO
}

\author{
Renato Luiz Hannisch \\ Daniela Patrícia Ado Maldonado \\ Jocyléia Santana dos Santos
}

RESumo Este artigo tem por objetivo descrever a implantação da instituição educativa Centro Educacional Martinho Lutero na cidade de Palmas/TO - instituição que aos 500 anos da Reforma Protestante completou 25 anos de atuação na capital tocantinense. Tem como recorte temporal o período compreendido entre os anos 1992 a 2004, considerados, na pesquisa realizada, como a época da implantação dessa unidade da Universidade Luterana do Brasil na capital do Tocantins. Trata-se de um estudo de caso, utilizando-se da metodologia história oral temática, recorrendo às memórias dos sujeitos que participaram do período e aos registros da memória acerca da história oficial produzida pela instituição. A pesquisa proporcionou conhecer diferentes aspectos da materialidade e da representação da instituição, além das aprendizagens vividas pelos seus alunos. Os relatos dos entrevistados proporcionaram poder conhecer: como o Centro Educacional Martinho Lutero procurou manter sua atuação face ao crescente número de instituições educacionais que passaram a atuar na capital ao longo do período; alterações na estrutura física, pedagógica e humana para manter-se no mercado educacional da capital em construção; e, como a confessionalidade luterana se fez presente ao longo desse tempo.

Palavras-chave: História Oral; Instituição Educativa; Centro Educacional Martinho LuTEro; Educação Confessional.

${ }^{\mathrm{I}}$ Universidade Federal do Tocantins. Palmas/TO - Brasil 
Abstract This article aims to describe the implementation of the educational institution Centro Educacional Martinho Lutero in the city of Palmas/TO - institution that at the 500 years of the Protestant Reformation completed 25 years of activity in the capital of Tocantins. The period between 1992 and 2004, research time-cut, is the period of implementation of this unit of the Universidade Luterana do Brasil in the capital of Tocantins. It is a case study, using the thematic oral history methodology, using the memories of the subjects who participated in the period and the records of the memory about the official history produced by the institution. The research provided insight into different aspects of the institution's materiality and representation. The interviewees' reports allowed us to know: how the Centro Educacional Martinho Lutero sought to maintain its performance in view of the growing number of educational institutions that began to operate in the capital throughout the period; changes in the physical, pedagogical and human structure to stay in the educational market of the capital under construction; and how Lutheran confessionality became present throughout the period.

Key-words: Oral History; Educational Institution; Centro EduCaCional Martinho Lutero; Confessional Education.

Resumen Este artículo tiene por objetivo describir la implantación de la institución educativa Centro Educacional Martinho Lutero en la ciudad de Palmas-TO - institución que a los 500 años de la Reforma Protestante completó 25 años de su actuación en la capital de Tocantins. Tiene como recorte temporal el período comprendido entre los años 1992 a 2004, considerados, en la investigación realizada, como el período de implantación de esta sede de la Universidade Luterana do Brasil en la capital de Tocantins. Se trata de un estudio de caso que utiliza la metodología historia oral temática, recurriendo a las memorias de los sujetos que participaron del periodo y a los registros de la memoria de la historia oficial producida por la institución. La investigación proporcionó conocer los diferentes aspectos de la materialidad y de la representación de la institución, además de los aprendizajes vividos por sus alumnos. Los relatos de los entrevistados permitieron poder conocer: como el Centro Educacional Martinho Lutero buscó mantener su actuación frente al creciente número de instituciones educativas que comenzaron a operar en la capital a lo largo del periodo; cambios en la estructura física, pedagógica y humana para mantenerse en el mercado educativo de la capital en construcción; y como la confesión luterana se hizo presente a lo largo del periodo.

Palabras clave: Historia Oral; Instituciones Educativas; Centro Educacional Martinho LUtero; EduCACIÓN CONFESIONAL.

\section{INTRODUÇÃo}

O Centro Educacional Martinho Lutero (atual Colégio ULBRA Palmas) é uma das unidades educacionais da Universidade Luterana do Brasil localizadas no Norte do Brasil. Com construção iniciada em 1992, essa instituição passou a oferecer em Palmas, capital do 
Tocantins, a partir de 1993, a Educação Básica e três cursos de Ensino Superior (Administração de Empresas, Letras e Pedagogia).

Em função do crescimento do número de alunos vivido pela instituição nos seus primeiros anos de atuação, gradativamente, a partir do segundo semestre de 1995, os cursos de Ensino Superior foram transferidos para um novo campus, construído para atender, especificamente, a esse segmento educacional da instituição, atual Centro Universitário Luterano de Palmas - CEULP/ULBRA (ULBRA, 2005b).

Dessa forma, a ULBRA Tocantins deixou de realizar suas atividades em um único campus, permanecendo o Centro Educacional Martinho Lutero, a partir do $2^{\circ}$. semestre de 1995, voltado, especificamente, à Educação Básica.

Portanto, o presente artigo tem como escopo a implantação e desenvolvimento do Centro Educacional Martinho Lutero, cuja história tem início com o Plano de Expansão da Universidade Luterana do Brasil para o Norte e Centro-Oeste do país, realizado em 1989 (BECK, 1994). Com base nos relatos dos sujeitos que vivenciaram o período, buscou-se reconstruir a história e conhecer como ocorreu a implantação dessa instituição educativa na incipiente capital Palmas-TO.

A pesquisa revela diferentes aspectos de uma instituição educativa, recorrendo aos relatos dos sujeitos que vivenciaram o período, baseou-se nos referenciais da história oral (BENJAMIM, 1987; ALBERTI, 1990; SILVEIRA, 2007), nos referenciais que tratam sobre memória (HALBWACHS, 1990; NORA, 1993; LE GOFF, 1996;) e nos referenciais que versam acerca das instituições educativas (OLIVEIRA; GATTI JÚNIOR, 2002; MAGALHÃES, 2004), entre outros.

\section{As bases teóricas e PRÁticas da PESQUiSa}

A pesquisa teve como objetivo descrever a implantação do Centro Educacional Martinho Lutero no contexto da construção de Palmas. A metodologia utilizada no estudo contou com o aporte da história oral, por compreender a importante contribuição que ela poderia trazer para atingir o objetivo proposto. A história oral é considerada uma metodologia de pesquisa que procura evidenciar a memória e a subjetividade dos atores sociais que vivenciaram um momento histórico (SILVEIRA, 2007). Consiste na realização de entrevistas com pessoas que puderam testemunhar sobre acontecimentos, conjunturas, instituições, modos de vida e outros aspectos da vida contemporânea (ALBERTI, 1990).

Benjamim (1987) enfatiza que, em geral, a História se dá a conhecer segundo o relato dos vencedores; não de acordo com o relato dos vencidos. Assim, a maioria dos atores dessa mesma História não tem rosto, permanecendo no anonimato. Para esse autor, porém, a história oral, como metodologia, torna possível buscar na memória e nas lembranças de indivíduos e da sociedade aquela parte da história que ainda não foi cristalizada, dando, portanto, voz aos diferentes atores que fazem parte da história.

Portanto, a escolha da história oral ocorreu por se compreender que ela é um instrumento capaz de coletar informações dos sujeitos que participaram dos processos de cons- 
trução da história da instituição educativa pesquisada - por intermédio dos professores, alunos e servidores que atuaram na sua implantação e no seu desenvolvimento.

Reconstruir a história, com base nos relatos dos sujeitos que vivenciaram um período, de acordo com Nora (1993, p. 9), é um grande desafio, pois "a história é a reconstrução sempre problemática e incompleta do que não existe mais", sendo possível, por meio dela, conhecer apenas aquilo que é relativo, que possui rastro, distância e mediação. Ainda, para esse autor, aquilo a que atualmente chamamos de "memória", na verdade, poderíamos chamar de "história", pois, quando buscamos algo na memória daqueles que participaram de um momento, essa já não é mais memória verdadeira, passando a mesma a ser uma "memória de papel", pois, "à medida em que desaparece a memória tradicional, nós nos sentimos obrigados a acumular religiosamente vestígios, testemunhos, documentos, imagens, discursos, sinais visíveis do que foi” (NORA, 1993, p. 15). Para auxiliar nessa compreensão, Parente (2007, p. 107) esclarece que:

[...] a memória nunca é uma reprodução exata dos acontecimentos do passado, mas, sim, um complicado e contraditório conjunto de representações, um modo de seleção do passado [...] um fenômeno construído coletivamente e submetido a flutuações, transformações, mudanças constantes.

Os registros, os documentos, aos quais hoje se tem acesso, fazem parte de uma produção coletiva (memória coletiva) e fazem parte da imagem que se queria transmitir - tanto de maneira imediata, quanto, ao longo prazo - sendo produzidos, de forma coletiva, nas relações existentes entre os grupos sociais (POLLAK, 1989). O domínio da memória coletiva tem origem entre os povos sem escrita, dando fundamento aos mitos de origens das etnias ou famílias, sendo guardadas, nessas sociedades, por "homens-memória", ordenando-se em torno de três grandes interesses: os mitos de origem (a idade coletiva do grupo), as genealogias (prestígio das famílias dominantes) e o saber técnico (fórmulas práticas ligadas à magia religiosa). Quando esses povos passam a fazer o registro escrito, a memória coletiva continua a se fazer presente, forjando, a partir de então, os documentos produzidos (LE GOFF, 1996).

Halbwachs (1990) observa que a memória individual também é forjada nos acontecimentos que tecem a memória social. Ou seja, a construção da memória coletiva interfere na construção da memória individual e vice-versa, e, de acordo com Le Goff (1996), a memória coletiva não é somente uma conquista, mas é, também, um instrumento e objeto de poder. Ainda, para o autor, a evolução das sociedades, após os anos 1950, clarifica a importância da memória coletiva, pois ela faz parte das grandes questões sociais das sociedades desenvolvidas e em desenvolvimento, das lutas de classes, lutas pelo poder, estando presente nos diferentes períodos históricos da humanidade.

$\mathrm{O}$ acesso à memória, na pesquisa em instituições educativas, para Fernandes (2011), pode revelar fatos que fazem parte do seu dia a dia, fatos que os documentos históricos que chegam ao nosso tempo não revelam. É por meio da memória preservada nos sujeitos que vivenciaram os fatos que se oportuniza a investigação do contexto histórico, das circuns- 
tâncias da criação da instituição, e, mais especificamente, "o edifício escolar: organização do espaço, reformas e eventuais descaracterizações; os alunos: origem social, destino profissional e suas expectativas; os professores e os trabalhadores da educação" (FERNANDES, 2011, p. 33). Considerando os diferentes aspectos das instituições educativas, Magalhães (2004) caracteriza a dimensão sociocultural como função central da instituição, o que envolve aspectos de transmissão e produção de cultura científica, como, também, a socialização e formação de hábitos e valores.

Entende-se que a pesquisa sobre a história e memória do Centro Educacional Martinho Lutero, ancorada nos relatos dos sujeitos que vivenciaram o período (1992 a 2004), revelou aspectos da trajetória da própria instituição, possibilitando compreender que:

\footnotetext{
[...] nada na vida de uma instituição escolar acontece, ou aconteceu por acaso, tanto o que se perdeu ou transformou, como aquilo que permaneceu. A memória de uma instituição é, não raro, um somatório de memórias e de olhares individuais ou grupais, que se contrapõem a um discurso científico (MAGALHÃES, 2004, p. 155).
}

Na presente pesquisa, utilizou-se, mais especificamente, a metodologia da história oral buscando respostas para um tema específico, o que a caracteriza como história oral temática. De acordo com Freitas (2006), a utilização da metodologia dessa forma (ligada a um tema) possibilita realizar entrevistas com um variado grupo de pessoas, "resultando em maiores quantidades de informações, o que permite uma comparação entre eles, apontando divergências, convergências e evidências de uma memória coletiva, por exemplo" (p. 21-22).

Como o objetivo da pesquisa buscava conhecer a história da instituição educativa Centro Educacional Martinho Lutero, tendo como recorte o período compreendido entre os anos 1992 a 2004, foram convidados diversos sujeitos, desde diretores, servidores administrativos, alunos e professores que tiveram algum tipo de ligação com a instituição no período e, que pudessem testemunhar sobre a história da mesma, fornecendo, portanto, uma versão sobre a história da instituição. Após aceitação do convite para participar da pesquisa, os entrevistados foram convidados a assinar o Termo de Consentimento Livre e Esclarecido - TCLE, e realizou-se a gravação das entrevistas, que foram conduzidas com base em um questionário semiestruturado. As entrevistas foram degravadas e transcritas seguindo os procedimentos metodológicos da história oral, assim como foi autorizada a sua utilização pelos sujeitos.

Como técnica utilizada na realização de pesquisas, verifica-se que a História Oral, além de contribuir para revelar partes da história que não são conhecidas ou foram silenciadas (intencionalmente ou não), pode contribuir oferecendo novos olhares sobre a história que já se encontra registrada, pois, obriga o historiador a levar em conta perspectivas nem sempre presentes em outros trabalhos, gerando documentos ancorados em pontos de vista individuais e diferentes da produção da história já registrada que chega até o nosso tempo (AMATO, 2006).

A singularidade da metodologia se encontra não na busca de verdades absolutas, mas, no fato de proporcionar o conhecimento de diferentes verdades e, contribuir para compre- 
ender como essas "diferentes verdades" foram construídas pelo sujeito histórico (SILVEIRA, 2007). Com a história oral, busca-se nos atores (pessoas, indivíduos) acontecimentos que comprovem uma sociedade e sua construção.

A análise dos dados obtidos por meio das entrevistas foi realizada de forma qualitativa, tornando possível conhecer diferentes aspectos da trajetória da instituição, os quais serão abordados a seguir.

\section{EduCAÇÃo CONFESSIONAL LUTERANA: da EUROPa PARA O TOCANTINS}

No mesmo período em que jesuítas aportavam no Brasil, durante o século XVI, a Reforma Protestante estava se expandindo na Europa, sendo uma de suas marcas a valorização da educação (SAVIANI, 2011; MENDONÇA, 2008). Transpondo os limites do continente europeu, a educação confessional protestante também aportou no Brasil com os imigrantes que aqui chegaram, especialmente após a Independência do Brasil (período Imperial). Durante esse tempo, porém, o país não tinha liberdade religiosa, figurando a hegemonia da Igreja Católica Apostólica Romana, a qual possuía o direito de manter templos, escolas confessionais, ministrar aulas de ensino religioso nas escolas públicas e manter instituições de caráter religioso (REHFELDT, 2003; SAVIANI, 2011).

As atividades das escolas confessionais protestantes, no início da atividade missionária protestante no país, pode ser considerada como um complemento natural à igreja, sendo sua instalação marcada por razões filantrópicas e, especialmente, doutrinais, pois "o analfabetismo era empecilho ao aprendizado da doutrina protestante, calcada na leitura da Bíblia, de livros e revistas denominacionais" (DREHER, 1999, p. 12).

A Proclamação da República do Brasil, em 1889, e a legalização da liberdade de culto no país tornou a imigração de não católicos mais atrativa do que nos períodos anteriores, possibilitando que diferentes confissões religiosas tivessem o direito de estabelecer igrejas, agremiações e institutos (REHFELDT, 2003). Com a liberdade religiosa, um dos grupos que passou a enviar missionários ao Brasil, a partir do ano 1900, foi a Lutheran Church Missouri Sinod - LCMS. Missionários norte-americanos aportaram no Brasil, buscando atender a imigrantes protestantes luteranos vindos da Europa, organizando congregações, paróquias e distritos, e, fundando, em 24 de junho de 1904, a denominação que mais tarde passou a se chamar de "Igreja Evangélica Luterana do Brasil" (REHFELDT, 2003).

Em 1911, uma das congregações filiadas à Igreja Evangélica Luterana do Brasil, a Comunidade Evangélica Luterana "São Paulo" - CELSP, com sede em Canoas-RS, começou a desenvolver atividades educacionais de Ensino Fundamental, atendendo, primeiramente, aos filhos dos seus próprios membros, pois muitos não entendiam bem o português, além de seus pais desejarem uma educação luterana (BECK, 1994).

Mais adiante, no ano de 1972, a CELSP iniciou suas atividades com a Faculdade Canoense de Ciência Administrativa, culminando, no ano de 1988, na criação da Universidade Luterana do Brasil - ULBRA, espalhando-se, além de localidades no Rio Grande do Sul, pelo Norte e Centro-Oeste do país (BECK, 1994). No mesmo ano em que foi criada 
a Universidade Luterana do Brasil, em 1988, ocorreu a criação do Estado do Tocantins (SANTOS, 2015), momento em que a ULBRA passou a planejar sua expansão para esse Estado da federação (BECK, 1994).

Mesmo que a Universidade Luterana do Brasil tivesse nascido dentro de um contexto de forte presença germânica, que via na educação um meio de manutenção da fé luterana e da língua teuta, quando ela se instalou no Tocantins, não se manteve presa a essas características. Pois, no período em que a Instituição planejou sua instalação em Palmas, em 1989 e, quando passou a ofertar o seu serviço educacional, em 1993, dedicou-se a realizar suas atividades educacionais com uma população formada por pessoas que provinham de diferentes locais do país e com uma cultura religiosa bastante diversificada, como relatado pelos sujeitos que participaram dos primeiros anos do Centro Educacional Martinho Lutero (TESKE, 2013; DOLNY, 2013; STÜRMER, 2016).

A educação confessional no antigo norte-goiano (atual Tocantins) havia se desenvolvido ao longo do século XX. Primeiramente, com a chegada dos dominicanos à cidade de Porto Nacional, onde fundaram, em 1904, o Colégio Sagrado Coração de Jesus. A educação confessional protestante tem seus primeiros registros na ação missionária da Convenção Batista do Norte, os quais implantaram uma escola de educação primária na cidade de Tocantínia, no ano 1936, seguidos por implantações de escolas da denominação presbiteriana, ao longo das décadas de 1960 e 1970, com a formação de núcleos urbanos ao longo da Rodovia BR 153 (DOURADO, 2010; SANTOS, 2012).

O período pós Proclamação da República, bem como, todo o período das décadas que sucedem o decorrer do século XX, foi marcado pelo intenso conflito de interesses envolvendo a questão da presença do ensino religioso na educação formal e o conflito de interesses em defesa da educação pública ou privada. Esses conflitos, mais uma vez presentes na época da elaboração da Constituição de 1998, que pode ser tomado como expressão de todo um período, é assim descrito:

Foram abertos novos mecanismos de transferência de recursos públicos para a escola particular. Além das verbas para as comunitárias, aprovadas na Comissão de Sistematização, esses mecanismos aumentaram através de, pelo menos, três dispositivos na adoção de bolsas de estudo para o ensino fundamental e médio na escola particular, 'quando houver falta de vaga e cursos regulares da rede pública na localidade da residência do educando'; na definição sobre salário-educação, quando estabelece que será aplicado no ensino público fundamental, mas que 'as empresas poderão deduzir desta contribuição aplicação realizada com o ensino fundamental de seus empregados e dependentes'; e, finalmente, na transferência de verbas públicas para as 'atividades universitárias de pesquisa e extensão'. [...] No segmento privado, se forem consideradas apenas as escolas confessionais, pode-se dizer, sem nenhuma restrição, que estas saíram plenamente vitoriosas. Garantiram o ensino religioso na escola pública e o recebimento de verbas públicas (FAVERO, 1996, p. 282-283). 
Infere-se que o período em que a Universidade Luterana do Brasil passou a se implantar na incipiente capital Palmas, em 1992, é marcado, também, por esses interesses, pois, a concessão de bolsa atleta, concessão de bolsa para dependentes de colaboradores e para aqueles que professassem a fé luterana, estão presentes nas atividades da instituição pesquisada, sendo, muitas vezes, consideradas políticas da própria instituição na ótica dos sujeitos entrevistados.

Observa-se que no período em que a Universidade Luterana do Brasil passou a implantar-se na incipiente capital do Estado, em 1992, teve como diferencial, desde o início de suas atividades, a oferta da Educação Básica e alguns cursos de Ensino Superior (TESKE, 2013), enquanto as demais instituições educacionais confessionais, católicas ou protestantes, ofertavam somente a Educação Básica - instituição que teve sua história desvelada no relato dos sujeitos que viveram o período.

\section{História e memória do Centro Educacional Martinho Lutero}

\section{Construção e início das atividades}

A história do Centro Educacional Martinho Lutero em Palmas tem início com o Plano de Expansão da Universidade Luterana do Brasil, em 1989 (BECK, 1994); e, quando o reitor Becker, tendo tomado conhecimento do projeto de construção de Palmas, resolveu conhecer pessoalmente o local da nova capital do Estado. Para tanto, encontrou-se com o governador do Estado do Tocantins José Wilson Siqueira Campos para adquirir uma área com vistas à implantação de um projeto educacional (BECKER, 2015).

O encontro do governador Siqueira Campos com o reitor propiciou ações imediatas, assim relatadas por Becker:

Bati à porta do Governador, bati à porta do Governador... Ele não sabia que eu estava indo para lá. Ainda, muito menos dos meus interesses para Palmas. Aí ele pergunta: "O senhor, é quem?" "Eu sou pastor da Igreja Evangélica Luterana do Brasil, sou o dirigente da Universidade Luterana eu estou aqui para ver do seu interesse, por que eu sou um aficionado pelo seu projeto... Saber se o senhor tem interesse em um educandário em Palmas?” Me chamou de louco (risadas...). Quem sabe seja! Quem sabe seja!... [...] Isso foi um ano antes de iniciarmos a construção... Nós iniciamos a construção em outubro de 92. Isso foi mais ou menos um ano antes, 91. Ele era governador, ele era governador de lá! Conversa vai, conversa vem, digo: "Olha, vamos examinar o projeto." Aí não tinha Ministério, não tinha Secretaria, não tinha nada disso. Era ele e os Deputados. "Olhe, eu vou te arrumar o terreno, te arrumar o terreno. Providencia o projeto". Eu disse: "Seria uma escola de $1^{\circ}$ grau, de $2^{\circ}$ grau e de $3^{\circ}$ grau". Só na época que eu fui para lá, foi antes de 91 , antes de 91 ... não tinha casa nenhuma. Só tinha lá uma construçãozinha onde também eles faziam a alimentação dos operários. Aí ele gerenciou a situação legal para uma área, que seria na JK. Ele tinha me mostrado onde seria o palácio. Aí, olha: "quanto mais próximo do palácio, melhor”. [...] Dá uns dois quilômetros do Palácio, era numa esquina, numa quadra, foi designado, então, o terreno. [...] Doação do governo, doação 
do governo com o compromisso da escola. Evidente, sempre há um vínculo que existe, daí, entre um e outro, compromisso mútuo que se conjuga para a conclusão do projeto (BECKER, 2015).

$\mathrm{O}$ relato do reitor Becker não permite saber o momento exato do seu primeiro encontro com o governador do Tocantins e detalhes do desenvolvimento das negociações para que a instalação do primeiro campus da ULBRA no Tocantins se realizasse. Mas foi, de acordo com o mesmo, importante para que se iniciasse a implantação de um projeto educacional luterano no Estado.

O diretor Teske (2013)1, responsável pela implantação do Centro Educacional Martinho Lutero, relata que essa negociação, apesar de iniciada durante o primeiro governo de Siqueira Campos, não foi efetivada durante seu mandato. A doação legal da área ocorreu somente no governo de Moisés Avelino (1991-1994):

Ocorre que a ULBRA tinha decidido de montar um campus em Palmas a partir de uma ideia do Becker [...] O Siqueira, naquela ânsia de prometer muita coisa, prometer para muita gente, prometeu para o Becker que, se ele implantasse a Universidade como era a vontade dele, aqui em Palmas, ele daria uma área, cederia uma área do governo... para a Universidade. [...] Isso foi em 89. [...] Palmas recém tinham sido abertas as ruas. [...] E foi nessa época que o Becker desceu aqui. E tomou a decisão: "nós vamos, de fato, vamos construir uma Universidade nessa capital". [...] Isso em 89. Não tinha nada... Tinha muito mosquito, muita poeira, e muita lama na época do inverno, na época chuvosa. De qualquer forma o Siqueira ficou na promessa, mas nunca cedeu nada, nunca indicou uma área sequer. Ele não cumpriu com o que ele tinha prometido para o ex-reitor, que era reitor na época. Mesmo assim a ULBRA decidiu implantar o campus. Então entraram em contato, novamente, à distância. E aí, o Siqueira, teve, na realidade, dois anos de governo, só. Era um governo provisório, até que [...] houvesse as eleições. Aí quem foi eleito, no caso, foi o Moisés Avelino. O sucessor dele foi o Moisés Avelino. E o Moisés Avelino, num documento, assina a destinação de uma área. Lá na Avenida JK, na AI 10, Área Institucional número 10, bem na beira da JK, onde hoje fica o Colégio ULBRA. [...] Aí eles decidiram em Canoas a criação do campus de Palmas... Não tinha nome. Era o campus de Palmas da Universidade... para iniciar em 92 (TESKE, 2013).

Como relata o diretor Teske (2013), o reitor Becker manteve a decisão de implantar a instituição em Palmas, apesar de não ter sido concretizada a doação do terreno, fato que ocorreu apenas no governo seguinte. Decisão que pode ser considerada arriscada para a implantação da ULBRA em Palmas. Entretanto, a expansão religiosa e os ganhos econômicos com a implantação da instituição na cidade pareciam promissores.

1 Convidado pelo reitor da ULBRA Rubem Eugen Becker, Wolfgang Teske aceitou o desafio de construção e direção do campus da ULBRA Tocantins ao longo dos seus primeiros anos (1992 a 1997). Teske, durante o período em que atuou na instituição era, também, pastor da Igreja Evangélica Luterana do Brasil, liderando o grupo religioso luterano surgido concomitantemente às atividades da ULBRA Tocantins. 
A construção do Centro Educacional Martinho Lutero avançou de tal forma que, no final do mês de novembro de 1992, era possível observar as primeiras fundações de salas de aulas e as primeiras armações de madeira sendo colocadas. Simultaneamente à construção do Centro Educacional Martinho Lutero, nos meses de novembro de 1992 a janeiro de 1993, outras situações tiveram necessidade de resolução para que o propósito educacional da instituição pudesse, de fato, ser alcançado:

E aí já veio a preocupação: O tempo tá curto e nós temos que divulgar o vesti-
bular. E aí vem outro dilema... E não só o vestibular, também o Ensino Médio e
o Fundamental. E aí veio a pergunta: Sim, eu tenho que preparar esses profes-
sores para trabalhar na instituição, uma escola, que queriam um perfil diferente.
Aí você tem que preparar os professores. "Sim, mas, e quem são os professo-
res? E quantos nós vamos ter, se não tem nem um aluno?". Você imagina: está
construindo e ao mesmo tempo você tem que chamar professor, mas não sabe
quantos chamar, porque não sabe nem quantos alunos vai ter e nem sabe se vai
ter aluno (TESKE, 2013).

Para o diretor Teske (2013), diversas inquietações fizeram parte do período de construção do Centro Educacional Martinho Lutero e, entre elas, o escasso tempo para a construção física, organizacional e humana, poderiam gerar incertezas sobre o real funcionamento dessa instituição. Para atender o cronograma de início das atividades educacionais, previstas para o primeiro dia do mês de março de 1993, de acordo com o diretor Teske (2013), "trabalhava final de semana, direto, à noite, muitas horas à noite". Esse foi o momento em que muitos trabalhadores da construção, liderados pelo presidente do sindicato da categoria, iniciaram uma greve.

Do relato do diretor Teske, infere-se que os trabalhadores, junto ao seu sindicato, possivelmente, buscavam melhores condições de trabalho em função da exaustiva jornada imposta na tentativa do cumprimento dos prazos para que a instituição pudesse cumprir seu cronograma de funcionamento.

De acordo com o relato de outros entrevistados, que também vivenciaram a construção de Palmas, ao longo da década de 1990 a cidade "era um canteiro de obras" (LÜDKE, 2014; ROSA, 2015; SOUZA, 2015). Entre essas obras, certamente, muitos operários foram contratados por empresas para construções públicas e particulares, visto muitos órgãos públicos e empresas particulares estarem em processo de implantação. Além disso, em função do grande número de pessoas que vinham a Palmas no período, infere-se que havia, também, muitas obras residenciais/comerciais acontecendo em Palmas e, entre estas, acredita-se que muitos trabalhadores não obtinham o cumprimento das leis trabalhistas nas funções que exerciam. Nessas circunstâncias, pode-se observar a importância dos trabalhadores se organizarem em um sindicato e reivindicarem os seus direitos trabalhistas.

Em função da recente criação do Estado do Tocantins e construção da capital Palmas, os sujeitos participantes da pesquisa relatam que, naquele período, "quase tudo faltava" (SOUZA, 2015; BORGES, 2015; FILIPAKIS, 2015). A área educacional, ao longo da dé- 
cada de 1990, também é citada pelo diretor Teske (2013), pelo diretor Lüdke² (2014) e pela aluna Filipakis (2015), como uma área de muita escassez e volatilidade de mão de obra. De acordo com os mesmos, não havia professores de determinadas disciplinas e, muitos profissionais da área educacional, depois de conhecerem a cidade ou residirem na mesma por um período, acabavam indo embora, normalmente, alegando a falta de infraestrutura da capital e seu comércio incipiente.

Como pode se notar nos relatos, os problemas sofridos pela nova cidade também foram sofridos pela instituição nos primeiros anos de implantação: carências de infraestrutura com salas de aula inacabadas, funcionários que chegavam e partiam da cidade, professores contratados às pressas, entre outros. Infere-se que tudo isso interferiu na qualidade do ensino oferecido pela instituição.

Para iniciar suas atividades na capital, a instituição buscou implantar, inicialmente, um currículo e uma proposta pedagógica declarada como "construtivista". Para a seleção e treinamento dos primeiros funcionários, o diretor Teske declarou:

Eu disse, "vamos fazer o seguinte: [...] vamos começar uma escola diferente, a proposta vai ter que ser outra". Porque, aí, simultaneamente, comecei a preparar a documentação para encaminhar para o Conselho Estadual de Educação. E aí, nós começamos. "Não, nós vamos ter música incluída no currículo. E nós vamos ter música desde os pequenininhos. Vai ter música”. Desde a primeira série, do que hoje é o primeiro ano do Fundamental, "nós vamos ter o inglês. E nós vamos fazer uma modificação, vamos começar com a proposta construtivista”. A professora Jussará Lummertz, que era diretora acadêmica em Manaus, ela tinha implantado isso lá, apesar de que isso não era prática da ULBRA nos outros locais. E eu já tinha tido alguns cursos em Belém e tinha estudado isso, de certa forma. Disse: "não, vamos fazer isso em Palmas, também". E, aí, nós implantamos na época, chamado construtivismo, hoje parece que é sócio-interacionismo. Enfim. "Não, vamos implantar isto". E eu sei que até hoje tem uma parte de resistência, porque nem professores conheciam a proposta. Aí, disse para a Jussará: "você vai ter que me ajudar, porque eu não sou pedagogo, você vai ter que me ajudar nisso". E ela veio para qualificar os primeiros professores. Isso, ainda, no mês de fevereiro, de noventa e três. Porque era uma incógnita: "quantos alunos nós vamos ter nessa escola?" e, simultaneamente, “quantos professores?" Quer dizer, essa discussão foi indo durante todo o mês de dezembro e janeiro (TESKE, 2013).

Com a decisão do diretor Teske em adotar no colégio a proposta declarada construtivista, o Centro Educacional Martinho Lutero realizava diversos projetos, tanto de curto como de longo prazo (exposições, feiras, passeios didáticos etc.), incentivando, ainda, os alunos à prática de diferentes modalidades esportivas, o que contribuiu para a implantação de um programa de esportes, em agosto de 1996 - tema que será abordado na sessão seguinte.

2 Lüdke foi diretor da ULBRA Tocantins de maio de 1997 a janeiro de 2004. A partir de 1999, confiou a direção do Centro Educacional Martinho Lutero à coordenadora pedagógica Noeli Stürmer, passando, o mesmo, a ter a função de "Diretor Geral da ULBRA de Palmas" (LÜDKE, 2014). 
Mesmo em meio às deficiências e carências de infraestrutura e mão de obra especializada vividas na capital, o Centro Educacional Martinho Lutero realizou os seus primeiros anos de atuação, estabelecendo-se como uma instituição educacional que, desde o início de seu funcionamento, em $1^{\circ}$. de março de 1993, ofereceu a Educação Infantil, a Educação Básica e, inicialmente, três cursos no Ensino Superior (Administração de Empresas, Letras e Pedagogia).

De acordo com Brito (2009), a formação populacional da cidade de Palmas ao longo dos seus primeiros anos teve pujança no discurso político e midiático, atraindo diversas pessoas para a mesma. Acreditava-se que a cidade teria, em meados da década de 1990, mais de meio milhão de pessoas. Fato que, de acordo com os dados estatísticos, não se concretizou. ${ }^{3}$

Segundo Cunha (2002), a taxa de imigração de Palmas, ao longo dos seus primeiros anos, apresentava a seguinte composição: $27 \%$ dos imigrantes vindos do Maranhão, $21 \%$ vindos de Goiás, $20 \%$ vindos do Pará, $7 \%$ vindos de São Paulo e 7\% vindos de Minas Gerais, caracterizando que, em termos educacionais:

[...] o perfil dos imigrantes é de uma maior concentração de pessoas nos níveis educacionais menos elevados, sendo os casos extremos Rondônia, Tocantins e Mato Grosso, onde mais de $40 \%$ desses indivíduos apresentava uma escolaridade menor que o primário completo, dos quais boa parte sem instrução alguma (CUNHA, 2002, p. 121).

Mesmo em meio às deficiências e carências de infraestrutura e mão de obra especializada vividas na capital, o Centro Educacional Martinho Lutero realizou os seus primeiros anos de atuação, estabelecendo-se como uma instituição educacional que, desde o início de seu funcionamento, em $1^{\circ}$. de março de 1993, ofereceu a Educação Infantil, a Educação Básica e, inicialmente, três cursos no Ensino Superior (Administração de Empresas, Letras e Pedagogia).

No início do ano de 1994, momento em que o Centro Educacional Martinho Lutero havia concluído seu primeiro ano de funcionamento, passou a ofertar os seus primeiros cursos de Pós-graduação lato sensu, iniciando com a Pós-Graduação em "Administração e Planejamento para Docentes" (COMUNICAÇÃO INTEGRADA, 1994). ${ }^{4}$

Ao longo do ano de 1993 e 1994, algumas edificações do Centro Educacional Martinho Lutero estavam concluídas, conforme Figura 1. Além disso, a capital Palmas estava recebendo investimentos na sua infraestrutura (galeria fluvial, pavimentação asfáltica, iluminação pública), especialmente na região central da mesma, como é possível verificar na ilustração que segue, que retrata parte da Avenida JK, o Centro Educacional Martinho Lutero e parte da Quadra 108 Norte (ARNE 13).

3 De acordo com as estatísticas, a cidade de Palmas possuía, em 1991, 24.334 habitantes (IBGE, 1991); em 1996, 82.977 habitantes (IBGE, 1996); e, em 2000, 137.355 habitantes (IBGE, 2000).

4 Os Cursos de Graduação e os cursos de Pós-Graduação, a partir do segundo semestre de 1995, foram, aos poucos, migrados para o novo campus da instituição, na Avenida Teotônio Segurado, permanecendo o Centro Educacional Martinho Lutero com sua atuação voltada para a Educação Básica. 
Figura 1 - Vista aérea do centro educacional Martinho Lutero, em 1994.

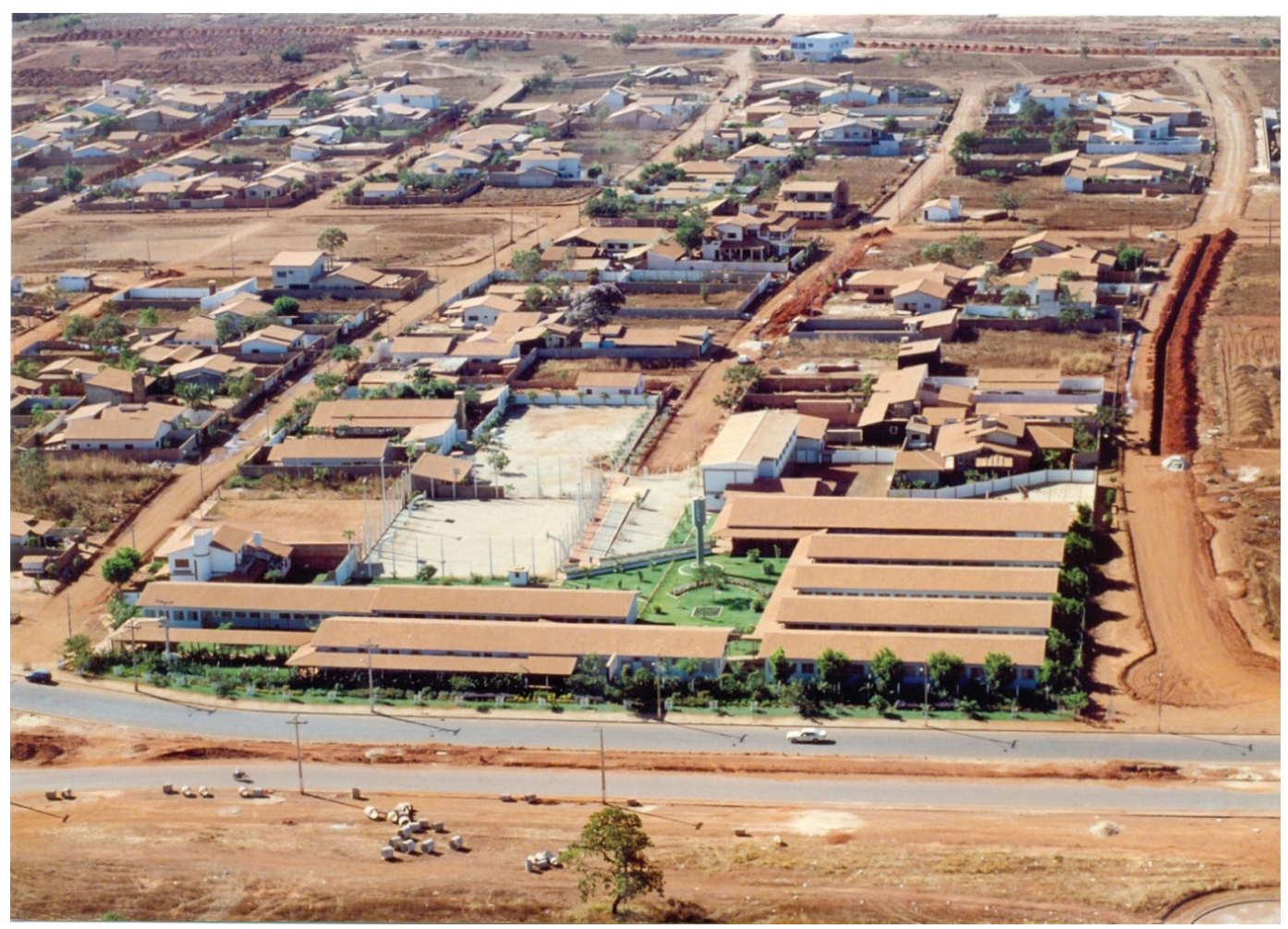

Fonte: Arquivo da Assessoria de Comunicação Social do CEULP/ULBRA.

No seu primeiro ano de atuação na capital Palmas, 1993, a instituição contou com 335 alunos matriculados na Educação Básica. Nos anos seguintes, 1994 e 1995, apresentou um significativo crescimento, especialmente entre 1993 e 1994, onde teve um aumento de mais de $130 \%$ no número de alunos da Educação Básica, contando com 778 alunos em 1994, e 808 alunos em 1995, conforme dados fornecidos pela Secretaria do Centro Educacional Martinho Lutero.

No ano 1996, o número de alunos do Centro Educacional Martinho Lutero apresentou um decréscimo de aproximadamente $47 \%$ em relação ao ano anterior, contando com 460 alunos. De acordo com alguns dos dirigentes do período, essa diminuição no quadro de alunos da Educação Básica se deveu às questões relacionadas à proposta político-pedagógica da instituição, que desde o início de suas atividades, em 1993, havia assumido a proposta político-pedagógica denominada pela instituição e pelos entrevistados como construtivista (STÜRMER, 2016; LÜDKE, 2014; ULBRA, 2005a; ULBRA, 2005b). Porém, sob a ótica da aluna Filipakis (2015), que foi aluna do Centro Educacional Martinho Lutero nos anos 1994 e 1995, a chegada de outras instituições educacionais à cidade de Palmas, a exemplo do Colégio Objetivo, foi motivo para que muitos alunos deixassem o Centro Luterano, especialmente para a conclusão do Ensino Médio. 
A aluna Rezende (2016) declarou que a educação oferecida no Centro Educacional Martinho Lutero, especialmente para as séries finais do Ensino Fundamental e para o Ensino Médio, não chamava tanto a atenção dos alunos que buscavam colocação em Cursos Superiores como Medicina ou em vestibulares mais concorridos, o que fazia que muitos alunos acabassem procurando outras escolas que, aos poucos, estavam se instalando na capital:

\begin{abstract}
Eu tive muitos colegas que, quando entraram para o Ensino Médio, optaram por sair daqui. Foram para outras instituições, por que achavam que aqui não cobrava tanto do aluno, que não exigia tanto. [...] O Colégio Objetivo, mesmo, tinha uma rivalidade com os alunos daqui, por se achar que estavam numa posição melhor. [...] Olha, eu lembro que na minha turma, na época, saiu. E falaram isso, sabe!? Que buscavam aprovação para Medicina, para cursos que iriam exigir mais (REZENDE, 2016).
\end{abstract}

Ao longo do ano 1996, buscando sanar a evasão ocorrida, o Centro Educacional Matinho Lutero tomou algumas medidas: assumiu, para o ano de 1997, uma proposta político-pedagógica denominada pelos entrevistados e pela instituição como progressista; implantou um programa de esportes, inaugurado, oficialmente, em agosto de 1996; e, passou por uma renovação de mão de obra, contratando pessoas que "dessem uma cara nova à instituição", como relatado por Stürmer (2016), que naquele momento havia assumido a coordenação pedagógica da instituição.

Infere-se que as medidas adotadas trouxeram resultados, contribuindo para que a instituição pudesse se manter no mercado educacional palmense, pois, de 460 alunos, em 1996, avançou para 640 no ano seguinte (dados fornecidos pela secretaria do Centro Educacional Martinho Lutero).

No primeiro semestre de 1997, o Centro Educacional Martinho Lutero passou, também, pela sua primeira mudança de direção, saindo o professor Teske, que havia assumido a instituição desde o momento de sua construção, em outubro de 1992, assumindo a direção do Centro Educacional Martinho Lutero o professor Lüdke, transferido do campus da Universidade Luterana do Brasil de Ji-Paraná/RO (LÜDKE, 2014).

No ano 1999, a professora Stürmer, que havia sido contratada como coordenadora pedagógica no momento em que a instituição buscava sanar a evasão de alunos, assumiu a direção do Centro Educacional Martinho Lutero, ficando o professor Lüdke com a função de "Diretor Geral do campus ULBRA de Palmas", cargo ocupado pelo mesmo até o início de 2004 (LÜDKE, 2014; STÜRMER, 2016).

Ainda durante o período em que o professor Lüdke foi o Diretor Geral do campus de Palmas, o Centro Educacional Martinho Lutero passou por outra renovação da sua direção, pois a diretora Stürmer, a fim de dedicar-se ao seu doutoramento, deixou a direção no início de 2001, que foi assumida pelo professor Raposo (LÜDKE, 2014).

Durante o período focado pela pesquisa, o Centro Educacional Martinho Lutero manteve um quadro flutuante de alunos, o que, de acordo com alguns dos entrevistados possuía diferentes motivos. Entre estes, destacaram-se: a chegada de outras instituições educacio- 
nais privadas à capital; o "clima de descrédito" vivido entre alguns habitantes da capital, causando a emigração de algumas pessoas que se instalaram em Palmas ao longo dos seus primeiros anos; e, também, internamente, a proposta político-pedagógica denominada construtivista, assumida pela instituição educativa ao longo dos seus primeiros quatro anos de funcionamento (FILIPAKIS, 2015; DOLNY, 2013; LÜDKE, 2014; STÜRMER, 2016; ULBRA, 2005a; ULBRA, 2005b).

O período em que a ULBRA decidiu pela implantação do Centro Educacional Martinho Lutero e, as mudanças que foram realizadas ao longo dos seus primeiros anos de atividade, tanto em sua estrutura material, no seu quadro de colaboradores, e, em sua proposta pedagógica, revelam como a instituição se desenvolveu na capital e como buscou manter sua atuação, especialmente a partir do momento em que outras instituições privadas passaram a figurar no cenário local.

Infere-se que as mudanças realizadas pela instituição ao longo do período podem ter ocorrido em função das perdas econômicas com a saída de alunos, especialmente entre 1995 e 1996, levando a instituição a adotar medidas na tentativa de sanar essa queda de alunos, bem como, implementar propostas que pudessem atrair alunos para os anos seguintes. Uma das propostas de manutenção no mercado educacional implementadas pela instituição foi o programa de esportes, iniciado em agosto 1996. Esse programa, aludido pelos entrevistados, será conhecido a seguir.

\title{
Programa de esportes
}

No período em que Stürmer veio a ser diretora do Centro Educacional Martinho Lutero, no ano de 1999, o programa de esportes da instituição já estava funcionando havia mais de dois anos. Sobre esse período, e como o programa de esportes interagia com a área pedagógica da instituição, Stürmer (2016) relata:

\begin{abstract}
A sala de dança com espelhos, a sala de judô, a quadra, que era quadra de basquete e de futsal, o tênis de mesa, também tinha a sala para tênis de mesa... era um diferencial que a ULBRA oferecia, que o aluno podia optar no contra turno para se inscrever em um programa e, alguns se destacavam, participavam de competições. Aí tinha alunos bolsistas. [...] Quando se deu toda essa ênfase para o esporte, a gente também teve embates pedagógicos com isso, mais uma vez. [...] Primeiro a gente colocou [...] critérios para participar dos programas de esportes e, um dos critérios, era ter bom rendimento escolar. Tinha que ter o rendimento escolar acima, não me lembro de que nível, para eles participarem. [...] Teve momentos que o professor Balú juntou a turma dele, grupo de basquete, deu aula de matemática. Ele mesmo deu reforço, espontaneamente. Quer dizer, assim, eu acho, eu olho isso hoje, e não existe. Porque o professor não tem nenhuma obrigação, nenhum treinador tem obrigação disso. Mas, assim, o grupo foi tão coeso e tão comprometido com o que a gente... E estabelecia critérios também (STÜRMER, 2016).
\end{abstract}

\footnotetext{
5 "Balú" era o apelido do treinador do time de basquete e coordenador esportivo do Centro Educacional Martinho Lutero, professor José Henrique Girotto.
} 
A diretora Stürmer (2016) aludiu que o programa de esportes, apesar dos embates com alunos que não tinham muito interesse nos seus estudos, transformou-se em um grande aliado da área pedagógica da instituição, fortalecendo os laços entre a instituição e os alunos e motivando os professores, especialmente os que participavam do programa, a se envolverem com a aprendizagem dos alunos e com o seu rendimento acadêmico.

$\mathrm{Na}$ visão do diretor Lüdke (2014), o programa, que se conjugava com as propostas pedagógicas assumidas pela instituição, trouxe contribuições para o comportamento dos alunos, causando "uma mudança radical" em alunos que não queriam estudar ou eram agressivos. Além disso, o programa trouxe contribuições para a própria instituição, pois, "a instituição se tornou muito conhecida através do esporte" (LÜDKE, 2014).

O programa de esportes adotado pelo Centro Educacional Martinho Lutero, em agosto de 1996, de acordo com o aluno Borges (2015), que passou a ser aluno da Educação Básica e atleta da natação do Centro Educacional a partir do ano 1997, foi responsável por conceder incentivos, por meio de bolsas de estudos, a diversos atletas, em diferentes modalidades esportivas ofertadas pela instituição: basquete, futsal, vôlei, judô, natação e tênis de mesa.

A respeito de sua participação nesse programa, o aluno Borges (2015) relatou que o seu primeiro contato com o Centro Educacional Martinho Lutero ocorreu em função dos esportes, e que permaneceu como aluno do colégio até o momento em que se tornou atleta profissional de natação, em 2001.

Na perspectiva do diretor Teske, o programa de esportes implantado em agosto de 1996 possuía três objetivos básicos: " 1 - desenvolver o esporte, integrando o aluno à sociedade; 2 - melhorar as condições de saúde; 3 - oferecer bolsas de estudo àqueles que se destacarem em qualquer modalidade esportiva do programa" (JORNAL STYLO, 1997).

O aluno Borges (2015), que participou de diferentes campeonatos de natação representando o Centro Educacional Martinho Lutero no período em que estudou na instituição (1997 a 2001), lembrou algumas de suas aprendizagens, vividas tanto por meio de atividades desenvolvidas pelo programa de esportes, como pela proposta educacional da instituição:

Eu lembro de viagens pela equipe da ULBRA, que a gente foi para Brasília sem os pais. [...] Mas acaba que isso aí vai gerando uma autonomia na gente, como pessoa, assim. E, talvez, seja a melhor lembrança e o que eu tenho de mais importante do esporte e de toda a minha formação na ULBRA: foi essa questão da preparação. [...] Com quinze anos eu já estava decidido que eu queria morar em um outro lugar, sem meus pais, e viver aquilo ali: natação. Então, assim, nunca tinha andado de ônibus aqui, lá eu comecei, ter que ir atrás de médico, ir atrás de coisas. Tudo isso, acho que a escola me ajudou a me preparar. Mais como cidadão, assim, do que para o vestibular. Eu acho que o que eu tenho mais, assim, de lembrança que eu guardo da minha formação na escola, é essa (BORGES, 2015).

Com relação às aprendizagens relatadas pelos alunos (BORGES, 2015; FILIPAKIS, 2015; REZENDE, 2016), e como o programa de esportes foi desenvolvido, infere-se que, em primeiro momento, seu objetivo era sanar a evasão de alunos ocorrida durante o ano de 
1996. Mas, também, infere-se que este programa trouxe desdobramentos na visibilidade da instituição, especialmente quando os meios de comunicação locais passaram a divulgar as conquistas alcançadas pelos alunos que participavam do referido programa.

Sobre esse Programa e seus desdobramentos, vale recordar, como afirma Magalhães (2004), que "nada na vida de uma Instituição Educativa acontece por acaso". Infere-se que, ainda que os objetivos iniciais e explícitos do Programa de Esportes fossem aqueles que o diretor Teske elencou (JORNAL STYLO, 1997), as ações do programa proporcionaram diferentes desdobramentos na trajetória da instituição e na vida dos alunos que vivenciaram o período.

\section{O Centro Educacional Martinho Lutero e a Confessionalidade luterana}

De acordo com o reitor Becker, a expansão da instituição, de Canoas/RS para o Norte e Centro-Oeste do país, tinha como objetivo principal "levar a Palavra para que ela chegasse ao coração do ser humano" (BECKER, 2015).

Essa finalidade tem grande ligação com o pensamento do reformador Martinho Lutero - de onde a instituição ULBRA herda seu caráter confessional - o qual defendia que a Educação deveria proporcionar aos jovens o conhecimento nas ciências e no verdadeiro culto a Deus, para que, assim, fossem capacitados a "governar igrejas, países, pessoas, casas, filhos e criadagem" (LUTERO, 1995, p. 330).

Buscando cumprir o ideal Educação x Missão que desde o início das atividades das denominações protestantes se fez presente em solo brasileiro (MENDONÇA, 2008), o Centro Educacional Martinho Lutero também se manteve firme a esse aspecto, fomentando a integração do grupo de luteranos que migrou para a capital e realizando a missão de evangelizar por meio de suas atividades educacionais (MÜLLER, 2013; TESKE, 2013).

De acordo com Dolny (2013), que foi um dos primeiros funcionários da ULBRA Tocantins e membro fundador da Congregação Evangélica Luterana Cristo Redentor de Palmas, o surgimento de um grupo religioso luterano e, posteriormente, a criação de uma congregação luterana, foi acontecendo aos poucos, paralelamente aos trabalhos desenvolvidos pelo Centro Educacional Martinho Lutero.

Encontros de membros da denominação luterana passaram a se realizar nas dependências do Centro Educacional Martinho Lutero ainda nos primeiros meses de 1993, poucos dias após o início das atividades educacionais do mesmo. Na ilustração (Figura 2), é possível identificar algumas famílias que participaram do primeiro culto luterano em Palmas: Teske, Müller, Figueiredo, Granetto e Dolny. Também se observa que, mesmo que o local já estivesse em funcionamento de suas atividades educacionais, o Centro Educacional Martinho Lutero ainda não estava com as construções concluídas, havendo máquinas utilizadas na construção civil nas áreas próximas aos blocos de salas de aulas e, com suas áreas internas ainda sem acabamento paisagístico, como pode se verificar na Figura 1 deste artigo (a Figura 1 corresponde ao período do $2^{\circ}$. ano de funcionamento da Instituição, 1994). 
Figura 2 - Grupo presente no primeiro culto luterano em Palmas, em 21/03/1993, realizado nas dependências do Centro Educacional Martinho Lutero.

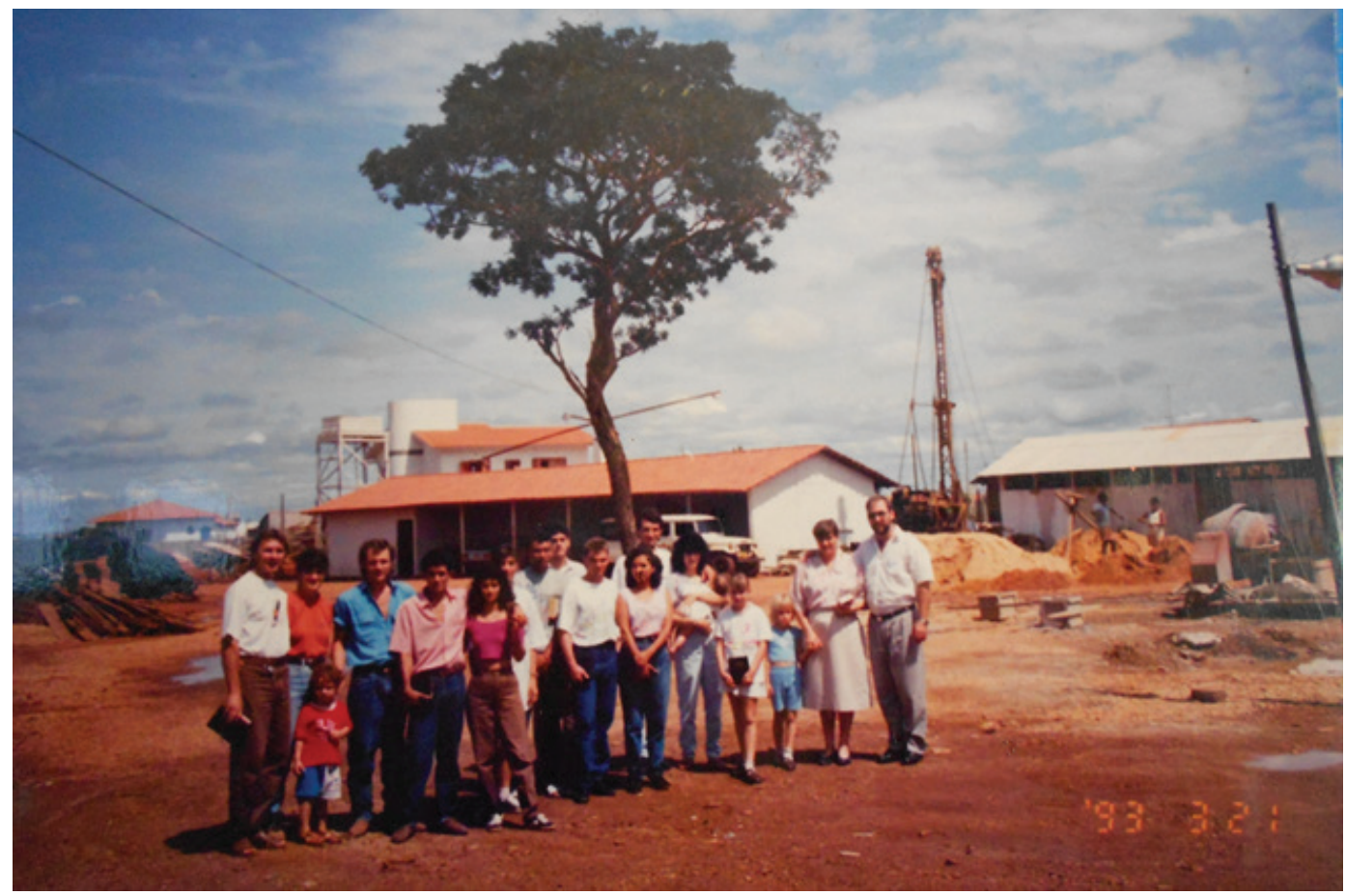

Fonte: Arquivo pessoal do Professor Wolfgang Teske.

No início de 1994, após um ano de atividades, a Universidade Luterana do Brasil tomou a iniciava de chamar um pastor luterano para o trabalho de capelania do Centro Educacional Martinho Lutero e, também, para auxiliar no trabalho da comunidade luterana de Palmas, que havia surgido e se formalizado ao longo do ano de 1993. Assim, durante os três primeiros anos, o grupo de luteranos residente em Palmas foi liderado, primeiramente, pelo diretor Teske (1993-1995) e, também, pelo capelão Pastor Milton Mauer (1994-1995), até que a comunidade luterana chamasse um pastor para exercer, especificamente, a liderança do núcleo luterano surgido nas dependências do Centro Educacional Martinho Lutero.

A decisão da Congregação Evangélica Luterana Cristo Redentor de Palmas para ter um pastor que pudesse atender ao grupo de forma mais intensiva ocorreu no segundo semestre de 1995, sendo chamado, para tanto, o pastor Laudir França da Rosa, o qual passou a dedicar-se ao trabalho da congregação local e, também, a ministrar aulas de ensino religioso no Centro Educacional Martinho Lutero (TESKE, 2013; ROSA, 2015).

$\mathrm{Na}$ avaliação do diretor Lüdke (2014) e do pastor Rosa (2015), o apoio dado pela Universidade Luterana do Brasil ao núcleo da denominação luterana de Palmas pode ser assim resumido: no começo das suas atividades, entre 1993 a 2000, além da concessão de seus espaços físicos para a realização de diferentes atividades religiosas e recreativas, 
houve a preocupação da ULBRA em prestar apoio espiritual aos adeptos da fé luterana que se encontravam em Palmas, destacando pessoas para atender o grupo existente. No período seguinte, de 2000 a 2004, além de continuar com o apoio físico e humano, há nos relatos a menção ao auxílio financeiro realizado pela Universidade Luterana do Brasil na construção do templo da Comunidade Evangélica Luterana Cristo Redentor, localizado nas proximidades do Centro Educacional Martinho Lutero.

Outro fato presente na relação entre a ULBRA Tocantins e a comunidade luterana local, conforme relatado pelo pastor Rosa (2015), é a concessão de bolsas de estudos para que membros luteranos pudessem estudar na Educação Básica ou nos Cursos de Graduação oferecidos na instituição.

Na avaliação do pastor Rosa (2015), muitas pessoas buscavam a comunidade luterana e se tornaram participantes da mesma por interesses em usufruírem a bolsa de estudos, o que, de acordo com o mesmo, acabava causando constrangimentos ao trabalho. Por sua vez, o pastor Rosa também enfatizou que o trabalho da ULBRA teve como resultado a conversão de estudantes e funcionários para a Igreja Luterana local, o que ocorreu independente dos benefícios relacionados à concessão de bolsas de estudos.

Para Filipakis (2015), que foi aluna do Centro Educacional Martinho desde o ano de 1994 e, anos depois tornou-se seguidora da denominação luterana, o aspecto confessional da instituição foi avaliado como algo que lhe deixava livre para fazer suas próprias escolhas, oferecendo-lhe orientação, sem, no entanto, coagi-la a tomar parte na confissão de fé luterana.

A diretora Stürmer (2016), que foi colaboradora do Centro Educacional Martinho Lutero entre os anos de 1997 e 2001, por sua vez, apontou para a importância desse aspecto na possível escolha da instituição por parte de algumas famílias que matriculavam seus filhos na mesma:

\begin{abstract}
Eu acho que a ULBRA, assim, ela tinha princípios que eram cristãos, e isso, de cara, derrubava paredes entre religiões. Eram princípios cristãos, eram valores... Eu mesma era católica. Nunca fui obrigada a ir em um culto. Eu ia em consideração, no mês do meu aniversário, porque eu sabia que iria ter uma oração especial. E participava, também, quando eu quisesse. E eu acho, assim, que isso foi, também, um dos aspectos que muitos pais avaliaram na hora de escolher a escola, porque ninguém se sentia constrangido por ser de outra religião. Nunca vi, assim, querer doutrinar alguém. Sempre foi o maior respeito, desde que as pessoas entendessem o sentido dos valores cristãos (STÜRMER, 2016).
\end{abstract}

Percebe-se que o caráter confessional da ULBRA Tocantins proporcionou aos participantes de suas atividades (colaboradores, alunos e seus familiares), a vivência dos valores que fazem parte de sua confessionalidade como instituição educacional cristã luterana, e que a instituição, desde o início de suas ações no contexto da capital Palmas, articulou-se para que esse aspecto da sua ação também pudesse estar presente em suas atividades, tanto no atendimento aos luteranos que migraram para a cidade, como nas suas programações voltadas para a comunidade escolar. 
Depreende-se, ainda, que, mesmo o reitor Becker (2015) aludindo o objetivo de "levar a Palavra para que ela chegasse ao coração humano", havia interesses diversos da instituição ULBRA em expandir suas atividades do Rio Grande do Sul para o Norte do país, para as "....regiões, que, comparativamente ao Sul e Sudeste, recebem pouca atenção de instituições particulares de ensino" (BECK, 1994, p. 52), tornando-se, assim, a implantação do Centro Educacional Martinho Lutero na incipiente capital uma estratégia arriscada em função dos investimentos financeiros realizados, mas, que, sob a ótica dos participantes do período, é memorada como parte de sua própria história nos primeiros anos de existência da capital tocantinense.

\section{CONSIDERAÇões FINAIS}

No ano de 1992, ano em que se completavam 475 anos da Reforma iniciada por Martinho Lutero na Europa, a ULBRA, com os ideais da educação luterana, iniciou, com o povo que chegava à capital Palmas, sua atuação na Educação Básica e Superior no solo tocantinense.

Com as características próprias de uma Instituição Educativa, que, assim como um ser humano que se angustia, que toma decisões e que faz planos (MAGALHÃES, 2004), a instituição "sonhou", planejando sua implantação e o início de seu funcionamento, na capital Palmas, para o ano de 1993 (BECK, 1994), buscando um vasto campo a ser explorado, visto, naquele momento, poucas instituições de Educação Básica ou de Ensino Superior estarem atuando na capital ou na região do antigo norte-goiano. Assim, infere-se que, em seus planos, havia um público diariamente crescente a ser alcançado em suas atividades, e que a instituição se articulou para alcançar esses planos outrora propostos.

Sobre a materialidade do Centro Educacional Martinho Lutero, pôde-se observar que o mesmo passou por diferentes mudanças, iniciando suas atividades de Educação Básica e Ensino Superior em um único campus, no ano de 1993, e, que, as ampliações e modificações realizadas até o ano de 2004 tiveram, entre outros, o objetivo que a instituição se consolidasse e se mantivesse no mercado educacional privado de Palmas.

Quanto aos aspectos abordados na pesquisa, foi possível conhecer que a Educação Básica da instituição assumiu duas propostas político-pedagógicas: uma de 1993 a 1996, denominada construtivista e, outra, a partir de 1997, denominada progressista - proposta que foi assumida pela instituição com o intuito de coibir a grande evasão de alunos, ocorrida especialmente entre os anos 1995/1996 - período em que o Centro Educacional Martinho Lutero teve 808 alunos e 460 alunos, respectivamente.

De acordo com a diretora Stürmer (2016), essa mudança na proposta pedagógica do Centro Educacional Martinho Lutero, assumida no início de 1997, foi positiva para a instituição, trazendo novos alunos para a mesma, e propiciando que novos projetos, fundamentados na proposta assumida, fossem vivenciados pela comunidade envolvida no processo educacional. 
Sobre as aprendizagens dos alunos que frequentaram o Centro Educacional Martinho Lutero, foi possível conhecer, por meio de seus relatos, alguns momentos vivenciados em sua trajetória educacional, como, por exemplo, o projeto de esportes da instituição. Mais especificamente sobre o projeto de esportes implantado na instituição em agosto de 1996, observou-se que este fez parte das estratégias adotadas pela instituição para sanar a evasão de alunos ocorrida entre 1995 e 1996. Infere-se que esse programa, aliado à mudança de proposta pedagógica, trouxe resultados imediatos e ao longo do período, visto a instituição ter projetado sua imagem nos meios de comunicação por meio de alunos que se destacaram em diversas modalidades esportivas, mas, que, o projeto também deixou marcas na aprendizagem dos alunos, contribuindo para a sua formação, como foi aludido pelo aluno Borges (2015) e pela diretora Stürmer (2016).

Por meio dos relatos, foi possível conhecer aspectos de sua história que não estão registrados em documentos, ou, quando registrados, não permitiam saber seus detalhes e sua riqueza. Infere-se que conhecer a história dessa instituição educativa e o início das ações luteranas no cerrado tocantinense, com base nos relatos dos sujeitos que vivenciaram esse período, tornou-se importante para que as memórias, ainda que sejam construções problemáticas e incompletas (NORA, 1993), pudessem ser alcançadas às gerações seguintes, possibilitando que novas interpretações e reflexões possam ser feitas - o que pode contribuir tanto para a educação laica como para o trabalho das instituições que se dedicam a realizar a educação confessional.

A importância da memória dos sujeitos participantes do estudo possibilitou poder conhecer a participação de sujeitos anônimos nos eventos, e, conhecer momentos que, a princípio, pareciam situações sem importância (motivos de alegria, de satisfação, de dor ou de angústia), mas que, a partir do momento da cristalização das memórias, puderam se tornar uma nova forma de ver a história da instituição e do seu desenvolvimento.

A utilização da metodologia proporcionou o conhecimento de "diferentes verdades" sobre a história da instituição pesquisada, revelando como essa articulou-se para a sua implantação e manutenção na capital Palmas. "Diferentes verdades" que só puderam ser conhecidas com o aporte da metodologia história oral temática.

$\mathrm{O}$ estudo permitiu conhecer que de modo diferente das primeiras atividades educacionais exercidas pela Comunidade Evangélica Luterana São Paulo - CESLP, iniciadas em 1911, na cidade de Canoas/RS, cujo trabalho educacional era voltado ao atendimento dos seus próprios membros e se caracterizava por um acentuado vínculo com o germanismo (BECK, 1994), o Centro Educacional Martinho Lutero nasceu em um contexto onde a maior parte dos seus alunos e colaboradores possuíam confissões religiosas não-luteranas. Mas, se infere que, ainda assim, manteve fortes traços do seu caráter confessional e com os objetivos Educação x Missão - característica do trabalho educacional das denominações protestantes que chegaram ao país durante os séculos XIX e XX (MENDONÇA, 2008) tendo grande participação na formação do primeiro núcleo da denominação luterana que foi oficialmente organizado no Tocantins e, buscando desenvolver o ensino-aprendizagem com os valores próprios de sua visão de mundo. 
Assim, por um lado, a instituição buscou cumprir a sua "vocação" (Beruf), de "anunciar a Palavra", como foi aludido no relato do reitor Becker (2015), mas, por outro lado, tomou a decisão de implantar-se em Palmas para realizar a oferta de um produto para um segmento da sociedade que tivesse condições de arcar com os custos próprios da educação privada, sendo pioneira na Educação Básica e Superior do Estado do Tocantins e, tendo ampla influência no surgimento do primeiro núcleo do luteranismo na cidade de Palmas.

Além da expansão da espiritualidade da fé cristã luterana, compreendeu-se que a instituição, ao planejar sua expansão e implantação na capital Palmas, buscava atender interesses econômicos internos, pois, após diversos investimentos em sua infraestrutura material e em treinamento de pessoal, articulou-se para conter a evasão de alunos ocorrida entre 1995 e 1996. Dessa forma, como um "organismo vivo" (MAGALHÃES, 2004), realizou reflexões, alterações no seu quadro de pessoal e implementou programas e propostas pedagógicas que permitissem conter a evasão e possibilitassem a continuidade de suas atividades como instituição educativa privada e confessional.

O Centro Educacional Martinho Lutero - instituição que, no quincentenário da Reforma Protestante adentrou aos seus 25 anos de atuação no solo tocantinense - continua a figurar entre as instituições que se dedicam a realizar a educação confessional na capital Palmas.

\section{REFERÊNCIAS}

ALBERTI, V. Manual de História Oral, 3. ed. Rio de Janeiro: Editora FGV, 2005.

AMATO, R. de C. F. Reflexões sobre a Escrita da História de Instituições Educativo-Musicais. Congresso Luso-Brasileiro de História da Educação, 6, 2006, Uberlândia. Anais... Uberlândia: UFU, 2006. p. 2.343-2.355. Disponível em: $<$ http://www2.faced.ufu.br/colubhe06/anais/arquivos/208RitaAmato.pdf $>$. Acesso em 29 mar. 2016.

BECK, N. As origens da Universidade Luterana do Brasil. Canoas: Ed. ULBRA, 1994. BECKER, R. E. Entrevista. Canoas-RS, nov. 2015.

BENJAMIN, W. Sobre o conceito da história. In: Magia e técnica, arte e política. Ensaios sobre literatura e história da cultura. Obras escolhidas, v. 1. Tradução: Sérgio Paulo Rouanet. Ed: Brasiliense, 1987, p. 222-232.

BORGES, G. R. Entrevista. Palmas-TO, nov. 2015.

BRITO, E. O papel de Palmas-TO na rede de integração regional, 2009, 262s. Dissertação (Mestrado em Geografia) - Faculdade de Ciências Humanas, Universidade Federal da Grande Dourados, Dourados, 2009.

COMUNICAÇÃO INTEGRADA: veículo de comunicação ULBRA. PÓS-GRADUAÇÃO. Palmas, p. 1, ano 1, n. 1, set. 1994.

CUNHA, M. P. da. Migração no Centro-Oeste Brasileiro: as tendências e características do 
período de 1986/96. In: HAGAN, D. J. (Org.). Migração e ambiente no Centro-Oeste. Campinas: Núcleos de Estudos de População/UNICAMP: PRONEX, 2002.

DOLNY, A. Entrevista. Palmas-TO, nov. 2013.

DOURADO, B. B. D. Educação no Tocantins: ginásio estadual de Porto Nacional, 2010. Tese (Doutorado em Educação) - Faculdade de Educação, Universidade Federal de Goiás/ UFG, Goiânia, 2010.

DREHER, M. A educação secular confessional: o diferencial da instituição educacional evangélica. São Leopoldo: EST, 1999.

FAVERO, O. (Org.). A educação nas constituintes brasileiras. São Paulo: Autores Associados, 1996.

FERNANDES, L. C. Novas tecnologias da informação e comunicação e a história da educação: um estudo de caso sobre história e memória de instituições escolares, 2011, 213s. Dissertação (Mestrado em Educação) - Programa de Pós-Graduação em Educação, Universidade Federal da Grande Dourados, Dourados/MS, 2011.

FILIPAKIS, C. D. Entrevista. Palmas-TO, dez. 2015.

FREITAS, S. M. História oral: possibilidades e procedimentos. São Paulo: Associação Editorial Humanitas, 2006.

HALBWACHS, M. A memória coletiva. São Paulo: Vértice, 1990.

IBGE, 1991. Censo Demográfico de 1991. Fundação Instituto Brasileiro de Geografia e Estatística. Disponível em: <http://www.ibge.gov.br/home/estatistica/populacao/censodem/default censo1991.shtm>. Acesso em: jun. 2016.

IBGE, 1996. Contagem Populacional de 1996. Fundação Instituto Brasileiro de Geografia e Estatística. Disponível em: <http://www.ibge.gov.br/home/estatistica/populacao/contagem/>. Acesso em: jun. 2016.

IBGE, 2000. Censo Demográfico de 2000. Fundação Instituto Brasileiro de Geografia e Estatística. Disponível em: <http://www.ibge.gov.br/home/estatistica/populacao/default censo_2000.shtm>. Acesso em: jun. 2016.

JORNAL STYLO. Pastor Wolfgang Teske, Diretor Geral da ULBRA. Palmas, p. 4, ano I, n. 5, fev. 1997.

JULIA, D. A cultura escolar como objeto histórico. Revista Brasileira de História da Educação. Campinas, 2001, n. 1, p. 09-43.

LE GOFF, J. História e memória. Campinas: Editora da UNICAMP, 1996.

LÜDKE, H. E. Entrevista. Palmas-TO, nov. 2014.

LUTERO, M. Obras selecionadas, v. 5. Porto Alegre e São Leopoldo: Concórdia/Sinodal, 1995. 
MAGALHÃES, J. P. Tecendo nexos: história das instituições educativas. Bragança Paulista: Editora Universitária São Francisco, 2004.

MENDONÇA, A. G. O Celeste Porvir: a inserção do Protestantismo no Brasil, 3 ed. São Paulo: Editora da Universidade de São Paulo, 2008.

NORA, P. Entre memória e história: a problemática dos lugares. Projeto História. São Paulo: PUC, n. 10, 1993, dez., p. 7-28.

OLIVEIRA, L. H. M. M.; GATTI JÚNIOR, D. História das Instituições Educativas: um novo olhar historiográfico. Cadernos de História da Educação, v. 1, n. 1, jan./dez. 2002.

PARENTE, T. G. Gênero e memória de mulheres desterritorializadas. Uberlândia: ArtCultura (UFU), v. 9, 2007, p. 99-112.

POLLAK, M. Memória, Esquecimento, Silêncio. Revista Estudos Históricos. Rio de Janeiro: Cpdoc/FGV, 1989, p. 3-15.

REHFELDT, M. L. Um grão de mostarda: a história da Igreja Evangélica Luterana do Brasil. Porto Alegre: Concórdia, 2003.

REZENDE, P. F. S. Entrevista. Palmas-TO, mai. 2016.

ROSA, L. F. Entrevista. Palmas-TO, dez. 2015.

SANTOS, J. S. A sedução da imagem: a televisão no limiar do Tocantins. Palmas-TO: EDUFT, 2015.

SANTOS, J. S. dos. História da educação nos primórdios tocantinos. In: MACHADO, M. M.; SANTOS, J. S. dos (Orgs.). Percursos históricos da educação no cerrado. Campinas-SP: Mercado das Letras, 2012.

SAVIANI, D. História das Ideias pedagógicas no Brasil. Campinas: Autores Associados, 2011.

SILVEIRA, É. da S. Pensando História Oral e memória um perfil de historiador etnográfico. MÉTIS, história \& cultura. Caxias do Sul, v. 6, n. 12, 2007, p. 35-44.

SOUZA, M. J. S. Entrevista. Palmas-TO, dez. 2015.

STÜRMER, N. M. Entrevista. Palmas-TO, jan. 2016.

TESKE, W. Entrevista. Palmas-TO, set. 2013.

ULBRA. Livro de Atas Reunião de Reitoria Norte e Centro-Oeste 1993 a 2005. Canoas-RS: Primeiro Livro, 2005a.

ULBRA. Livro de Atas Reunião de Reitoria Norte e Centro-Oeste 1993 a 2005. Canoas-RS: Segundo Livro, 2005 b.

ULBRA. Resoluções do Conselho Universitário: 1988 a 1993. Canoas: Ed. ULBRA, 1995. 


\section{Dados dos Autores:}

\section{RENATO Luiz HANNISCH}

Universidade Federal do Tocantins. Palmas/TO - Brasil

Graduado em Teologia pela Universidade Luterana do Brasil (2010), Especialização em Metodologia do Ensino na Educação Superior pela UNINTER (2012), Mestrado em Educação pela Universidade Federal do Tocantins (2016). Palmas/TO - Brasil renatohannisch@ig.com.br

\section{Daniela Patrícia Ado Maldonado}

Universidade Federal do Tocantins. Palmas/TO - Brasil

Graduada em Psicologia pela Universidade Federal de São Carlos (1999), Mestrado em Educação Especial (Educação do Indivíduo Especial) pela UFSCar (2003), Doutorado em Educação pela Universidade Estadual Paulista Júlio de Mesquita Filho - UNESP (2011). Palmas/TO - Brasil ado_daniela@yahoo.com.br

\section{Jocyléia Santana dos Santos}

Universidade Federal do Tocantins. Palmas/TO - Brasil

Graduada em História pela Universidade Católica de Goiás (1991), Mestrado em História pela Universidade Federal de Pernambuco (1996), Doutorado em História pela Universidade Federal de Pernambuco (2006). Palmas/TO - Brasil. jocyleiasantana@gmail.com

Submissão em: 30/05/2017

Aceito em: 30/03/2018 